\title{
Strategy Implementation in Organizations: A Conceptual Overview
}

\author{
PUSHPA RANI \\ University of Oulu, Finland \\ pushpa.rani@oulu.fi
}

\begin{abstract}
The strategy implementation procedure is one approach through which managerial objectives, methods, and rules are implemented throughout the growth programs, financial plan, and procedure. The organization can quickly fail if such strategies are not executed well. When an organization plans to implement the required strategic plan, it certainly addresses all the predicaments that the organization may face like the probability of misusing the inadequate capital or the risk of self-worth in case the business fails. In essence, the conceptual study presents the strategy implementation process to enhance the attainment of the mission and the vision of the business through quality products and services that increases the customer base. Therefore, the result of the paper shows that the firm should implement an excellent strategy to achieve the entire objective to meet all the goals of an organization.
\end{abstract}

Key words: strategy implementation, planning, strategic plan, mission and vision

https://doi.org/10.26493/1854-4231.14.205-218

\section{Introduction}

Strategy implementation is the stage where the real action in an organization is executed through the strategic management process (Allio 2005). It is the set of activities where the strategic plan is changed into strict performance in an organization. However, strategic change in planning is important, but the process is a little bit challenging. As Brinkschröder (2014) says, 'organizations invest a lot of time and resources in the planning of strategy, but very little of it will get successfully implemented.' Therefore, the study indicates that it is one of the critical aspects of any business success (Lubis, Torong, and Muda 2016); as it required the most attention understand of the strategy and its acceptance by implementers (Misankova and Kocisova 2014, 865). Implementation deals with the issue of who, where, when, and how (Allio 2005) to achieve businesses' 
objectives (Misankova and Kocisova 2014, 862). During the process of strategic implementation, the whole organization is involved to ensure that there is a collaborative operation. According to Van der Kolk and Schokker (2016), strategic management is the most meticulous and challenging constituent of the whole considered supervision approach and the one which needs a lot of input to enhance the progress of an organization (Van der Kolk and Schokker 2016). It requires all-inclusive plans to ensure that all the objectives of the organization are achieved. In essence, this paper presents a brief strategy implementation process; it reviews critical features of the strategic implementation methods, including strategy implementation factors, strategy implementation process, and factors that lead to the failure of strategy implementation. Lack of clear common understanding of overall aims and plans as a major barrier to strategy implementation (Brinkschröder, 2014). In any organization, the plan might be incredibly complex (Dunlop, Firth, and Lurie 2013), but understanding the implementation process may lead to be effective and therewith successful (Brinkschröder 2014).

\section{The Process for Implementing Strategy in an Organization}

\section{THEORETICAL BACKGROUND}

Successful organizations across the world such as the Coca-Cola Company implement strategic plans to ensure that the organization operates proficiently. Such approaches create a vision for the future, and the methods required attaining all the stipulated goals. However, there are still some organizations, which are unable to understand the vision and the mission of the organization, and they fail to deliver the required services (Grant 2016). Unluckily, the managerial team may fail to pinpoint all the reasons for the failure of the business, believing that repeating the strategic planning time to time will have better results. In most cases, such an approach does not work (Deraman et al. 2017). Therefore, there is a need to ensure that strategic methods are implemented to attain maximum results. To do so, five significant constituents support the effective execution of strategies. People, resources, structure, systems, and culture are some of the factors that support strategy implementation in any firm (Palinkas et al. 2015).

The human resources/personnel are the people tasked with carrying out the company's strategy. The team must be adequate in size and must have the skills, competence, and commitment necessary to bring the policy to fruition. According to Rani and Mishra (2014), 


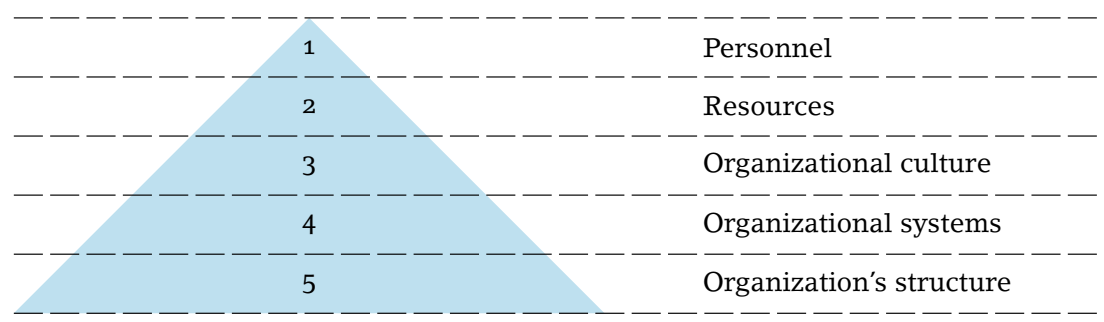

FIGURE 1 The factors to Support the Strategy Implementation

the quality of the team is a critical part of the success of the organization's plan. The organization should not only have people to execute its stipulated goals; they must be proficient enough who have the requisite skills to enhance the attainment of the stipulated goals in an organization. A research done by Lubis, Torong, and Muda (2016) indicates that the number of people in an organization is an issue that is easy to address since one can hire new workforce ( $\mathrm{Lu}$ bis, Torong, and Muda 2016). The major problem is seeing that one has the right people with the right skills, knowledge, and capability needed in implementing the task that would execute the strategy. Because in an organization, having the right employees will greatly enhance the likelihood of success (Aspridis and Kyriakou 2012, 21).

The firm must further have enough resources with regard to funding and time. The most significant undertaking in strategy implementation is the provision of assets, which is in the form of monetary or non-monetary resources obtainable in an organization. In addition, there are economic and non-economic resources that lack in an organization, and they are still required for strategy implementation (Powell et al. 2015). During the strategy implementation, the first thing that comes into the mind of an individual is the amount of money needed to support the application by covering all the costs and the expenses that should be acquired during the implementation of the strategies. Another critical resource is time (Lubis, Torong, and Muda 2016). There should be enough time to ensure that the policy is implemented throughout the process. As such, it creates an environment where all the undertakings can be tactically planned to achieve all the objectives.

Cristian-Liviu (2013) stated that the organizational structure ensures that the firm has the right attitude, tools, and structure that support the implementation of the strategy. Moreover, the structure of the organization must have comprehensible and in line with the ability and the accountability clear and highlighted in the order 
of the objectives of the organization (Cristian-Liviu 2013). All the members of an organization must understand their responsibilities, and they must be accountable for them. Specifically, supervisors are evaluated on business formation, work quality, communication capability, credibility and other factors (Aspridis and Kyriakou 2012, 28). Additionally, the management should also describe the lines of communication in the entire organization. Workers in all areas of specialization should communicate well with other departments and supervisors so that they can achieve the objectives of the firm as a team (Powell et al. 2015). Ensuring that there is clear and open communication among the employees and the managers creates transparency, and people can share different ideas especially on issues that may affect the progress of the firm and how to address them. Open communication allows debate, argument, support and feedback, enthusiasm and as well as personal warmth for clear understanding (Arzenšek and Košmrlj 2017).

The culture of a business is another issue that supports policy execution practice. It is the general atmosphere within an organization concerning its associates. The organization should make its workers feel essential and contented in their particular responsibilities. For instance, they can be concerned with the premeditated administration method and play a critical role in ensuring that they are engaged in issues like decision-making. A custom of being responsible for different practices increases the motivation of the workers, and they improve their performance. It creates an environment where everyone feels inspired to contribute to the implementation of the approaches required to achieve the objectives of the enterprise (Deraman et al. 2017). For instance, some firms have the performance of appraisal as their central culture whereby, they reward the best performing workers by paying them or promoting them in their different departments. Such culture creates an environment where workers are to improve their competency to get the same favors from the organization.

\section{STUDY PREPOSITIONS}

Factors, which support strategic implementation, are generally in conformity with the significant achievement aspects required for successful execution. There are approaches classified by McKinsey that determine how best to implement a proposed strategy (Misankova and Kocisova 2014) in a firm. In essence, there are McKinsey 7s Framework factors (Jurevicius 2013) that increase the sustainability of any organization. The McKinsey as a tool made to give answers 
to any questions that concern the design of the enterprise (Yeoh and Popovič 2016). The primary aim of the structure is to answer questions concerning the organizational design. The importance of the model is to coordinate the organizational structure that also supports how strategy implementation is portrayed. It entails the entire organization and not particular departments. It is an inclusive approach that engages all people in the organization and creating a strategy that people can work as a team instead of a single entity (Tarhini et al. 2015). In essence, the seven factors also play an essential role in implementing strategies in any organizational effectiveness.

The plan of any organization to attain a viable gain and sustainable development must be well elaborated for the enduring achievements of the business. The policy must be clear to all the employees and employers to ensure that everyone in the firm works towards the stipulated objectives (Netland 2016) and to focus their development efforts on organizational success (Ha-Vikström 2017). Notably, when an organization addresses its mission and vision, the strategy must be in line with them so that all the set goals can be achieved without any problem. A clear plan in an organization shows the core values and define how to make it unique in providing services to the people (Yeoh and Popovič 2016). In essence, other organizations may offer the same services, and thus it requires uniqueness to gain a competitive advantage in any market.

Shared values are another crucial constituent in the course of applying the plans in the business. It is a significant part of the McKinsey $7 \mathrm{~s}$ framework. The principles, customs, and normally conventional attitudes eventually encourage members of the firm to carry out their practices in a particular manner. These standards and customs will control workers' personalities, and their shared values will be the major factors that enhance the prosperity of the business (Tarhini et al. 2015). When people, for instance, share common goals, it becomes easy to work as a team. Sometimes, it becomes challenging to achieve all the objectives that an organization would want to, but with the shared values amongst the workers, it becomes easy to attain.

To guarantees an effectual completion of policies, it is critical to have a system that is followed. The study indicates that the strategy implementation process is a five steps approach that involves strategy evaluation and communication of the strategic plan, development of an implementation structure, development of implementation-support policies and programs, budgeting and allocation of resources and discharge of functions and activities. Some researches 
FIGURE 2

Five Different

Approaches during

Strategy

Implementation

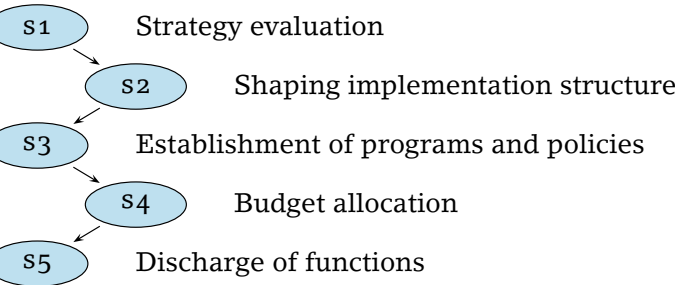

indicate that implementation of strategies is more critical than the procedures themselves (Spink et al. 2016).

\section{STRATEGIC IMPLEMENTATION APPROACHES}

However, it is not about trying to understand what is better is better than another is, since all the approaches are critical in strategic management. Formulating winning approaches is the most vital approach that any organization can implement to ensure that there is a competitive advantage in such an enterprise.

1. In figure 2, the first approach in the strategy evaluation process involves the evaluation and communication of the strategic plan. At this point, the business looks into inputs, performance, budgets, or any other aspect of the firm's objectives or goals that were missed during the strategy formulation stage. Often, a business may need to adjust its plan based on unforeseen happenings. For example, the strategy may stipulate that a given duration time or several team members are required for a marketing drive. Different steps are undertaken during this process (Seale, Broutet, and Narasimhan 2017). For instance, one should support the plans with the proposals by ensuring that the policy on the plan aligns with the goals of the business. The step should also align the budget to the yearly goal. Monetary evaluation should be done and approved to offer insight on the best approaches to implement in using the money (Shomali and Peeples 2018). The budgetary issues should be done to ensure that the objectives of the organization are achieved. Additionally, one should communicate and explain the purposes of the organization to all the members. Such an approach ensures that people have a common objective and they are working towards them.

2. The second approach entails the development of the implementation structure. This step involves the fashioning of a structure that will guide the team or provide a framework on how 
the strategies will be implemented. Any good plan needs a frame or a playbook where all actions of workers take place (Brinkschröder 2014). All team members must be cognizant of their roles and how these affect the overall success of the strategy (Herrera-Sánchez, León-Pérez, and León-Rubio 2017). A structure aids the team in this object. Additionally, this step builds a vision that guides the framework of the implementation of the approaches needed in strategic planning. There should be an established harmonization system among different departments and their particular divisions. Such an approach enhances the designation of authority and accountability (Spink et al. 2016). Formulating the labor policy and strategies to be tracked in the execution of projects and identifying the major supervisory tasks and errands to be done and the skills required is also another approach, which is critical in the strategy implementation. It creates an environment where all members of the firm are involved in decision-making and the progress.

3. A research done by Shomali and Peeples (2018) indicates the development of implementation-support policies and programs are also referred to as strategy motivating guidelines or steady development programs. They are policies and programs, which enhance the implementation of proficient approaches in an organization. Here, the business comes up with constant improvement programs or policies that support the implementation of the strategy (Herrera-Sánchez, León-Pérez, and León-Rubio 2017). While an approach may be concrete, it can always be improved; the essence is the essence of establishing programs and policies to keep maintaining competitiveness (Misankova and Kocisova 2014) and it may lead an organization towards success. A performance tracking and scrutinizing system should be developed. It acts as the foundation for monitoring success through what has been achieved and what it ought to be made (Seale, Broutet, and Narasimhan 2017). Additionally, an organization should establish a performance executive scheme, information, and response structure, which will collect all the information needed and involve workers in the aspect of performance and management.

4. The fourth step is the time where strategic management teams are equipped with the needed apparatus and another capacity to execute their primary responsibilities for performing tasks (HaVikström 2017). In essence, the team is equipped with appli- 
ances, funding, or any other resources necessary for implementing the tasks for the business process. This step is one of the most critical parts of the strategy implementation process where, business processes can help organizations vastly improve their effectiveness (Ha-Vikström 2017). The team and even the strategy may be substantial, but if these lack the resources and tools to implement; the likelihood of success significantly decreases (Shomali and Peeples, 2018). Excellently, the team should have well-working abilities and established with adequate resources if the plan is to reach fruition. Resources should be allocated to different departments, and financial assessments and documentation are done to ensure that there are no losses and inaccurate calculations in an organization. In addition, there should be a system that checks the financial balances and monitoring if all departments operate within the planned budget. As such, it becomes easy to allocate the required amount of funds to different departments and using the money well since there is a financial plan.

5. At this point, the team acts, and the strategy becomes operational. Factors such as leadership and participation of the group are crucial at this stage of strategic management. During the whole process, the organization must ensure that there is a constant engagement of the workers by offering training and orientations on the critical undertakings that should be implemented in an organization (Chang 2006). In addition, there should be appropriate managerial approaches in the performance of all the activities. The performance should be evaluated at all levels to recognize the gaps that may exist and implement corrective actions so that it may not happen again in the future (Shomali and Peeples 2018). The study indicates that it is essential to adopt early corrective measures in an organization to avoid future challenges in implementing strategies. Fundamentally, the results or achievements in step five are the inputs in the subsequent level, which is the third phase of tactical administration of plan assessment.

\section{Implications and Limitations}

\section{COMMUNICATION AS AN APPROACH}

The study indicates that nine out of ten businesses fail even with the best plans and approaches. Tourish (2014) postulates that the disconnect in leading the team and poor communication between 
management and employees is a major cause of business failure. Many factors lead to failure in strategic implementation. Some of the most common aspects include a disconnect between management and employees, poor leadership, lack of communication between team members, a convoluted and confusing plan, lack of ownership of critical parts of the program by team members and a disconnect in the strategy. For any project to reach fruition, the above factors must be tackled conclusively.

While there is a multitude of factors that may lead to strategy implementation failure, this factor of leadership must be placed in the first rank. Weak team leaders, regardless of the quality of his team, will likely bungle the best plan. Aside from the quality of leadership, the type of leadership has been known to influences strategy success. A transactional leader is mostly concerned with the performance, organization, and supervision of the group (Chang 2006). A transformational leader, on the other hand, is keen on aspects such as motivation of employees, engaging the team, and encouraging behavior operating as well as activate the firm resources towards the fulfilment of the organization's mission (Ha-Vikström 2018, 71). Fundamentally, these leadership strategies affect the success of a business divergently.

\section{TRANSACTIONAL MANAGEMENT APPROACH}

The transactional management approach has a constructive significance on the achievement of a business, while transformational leadership style affects the business negatively. It is imperative to note that $\mathrm{Li}$ and colleagues (2016) argued that group-focused transformational leadership harmed individual innovation and thus, overall strategy success. In effect, while transformational leadership leads to high levels of team satisfaction; it does very little to overall strategy success (Mkheimer 2018). All factors held constant; a transactional leadership style tends to avert failure in strategy implementation. In the end, failure in strategy implementation is almost always traced to the quality and style of leadership (Netland 2016). A team that communicates ineffectively or, lacks ownership often signals a laxity in administration or the type of leadership.

For business growth, the relationship between employees and managers is a crucial factor in the happiness and satisfaction of the employees in a firm (Öztürk and Demirkaya 2017). Sila and Širok $(2018,127)$ stated that the greater their satisfaction and the better the result. As dissatisfaction may lead to a lack of understanding also may affect the organizational structure and its strategy. There- 
fore, the incompetence of employees and managers, strategy disconnection, and little attention by management is the significant causes of failure in the implementation of strategic management. When the workers and the managers fail to understand the strategy, they also fail to understand the mission and the vision of the firm (Mkheimer 2018). However, a lack of communication may be as a result of a lack of understanding and openness between the senior management and the strategic management personnel. In addition, sometimes a lack of ownership of the people to implement the strategy may hard to make the decision and policy, which affects the working process and productivity (Sila and Širok 2018, 116) for business development. Since the workers and employers do not understand the policy; they may not have the incentive to work towards the goals of an organization. The strategy may also be disconnected such that there are no critical aspects such as budgeting and workers' compensation, which may enhance their motivation to work towards the set objectives (Li et al. 2016). Lastly, little attention by the management is a significant predicament that strategic management faces. Most of the managers do not understand all that the approach entails, and they do not create time for the same. For instance, they may not refer to the strategic plan since they do not understand all that it entails.

The process of implementing the strategy in an organization is critical in the development of any business. The approach offers the basis for the practices of the company, thus affecting the performance of the firm. The primary critical aspects of strategic planning include the vision, mission, values, and approaches implemented for the advantage of the organization (Springfield 2017). Additionally, apart from the other concerns of the strategic planning, the other undertakings of the firms entail the timelines of the policies, and other variables such as the business plan which enhances the development of such business (Springfield 2017). The primary significance of such an approach is to develop a strategic plan that, favors the condition of the firm based on the precise assessment of the internal and the external factors that may affect the operations of the business.

\section{FUTURE RESEARCH}

The lack of understanding and communication may lead to a lack of trust between managers and employees (Daghfous, Belkhodja, and Angell 2013), which leaves the gap for further research. Future research will identify the strategic planning process and managerial performance to determine the relationship between the practices 
of the managers and the strategic planning strategy. It will emphasize on the executive performance or management performance in any organization. For instance, to take or to assuming all the management responsibilities of the business firm (Basol and Karatuna 2017) can enhance an efficient strategic planning process (Springfield 2017). Additionally, future research will address strategic planning and human resource management since they are the main factors to consider for strategic management. Furthermore, it will look at the strategic planning and organizational performance and how it affects directly to an organization. The last question that the research will address is the strategic planning and business viability (Springfield 2017) in detail. The study indicates that strategic planning affects the viability and attractiveness of the trade for the workers. It creates an environment where the business can progress, and it should be adequately addressed.

\section{Conclusion}

The strategic implementation process is a critical part of the success of any firm. This work briefly reviews a few aspects of the strategic implementation process. Specifically, the work examines factors involved in strategy implementation, the strategy implementation process, and factors that lead to strategy implementation failure. The works show that any effectively implemented business strategy relies on five critical factors including the team charged with implementing the policy, the resources that will help the group affect the procedure, and the organization's culture, systems, and structure. Weakness in any of these facets often spells doom for the business. This work underlines that the strategy implementation process is a delicate five-step process involving strategy evaluation, the fashioning of the implementation structure, the establishment of programs and policies that support strategy implementation, budget allocation, and finally, the discharge of functions. Lastly, the work highlights factors that contribute to failure in strategy implementation. Poor leadership and lack of communication are, by far the most significant cause of failure. Others are a confusing plan, lack of ownership of critical parts of the project by team members, and disconnect in the strategy. In the end, this work shows that strategy implementation is a crucial aspect of the success of the firm.

\section{References}

Allio, M. K. 2005. 'A Short, Practical Guide to Implementing Strategy.' Journal of Business Strategy 26 (3): 12-21. 
Arzenšek, A., and K. Košmrlj. 2017. 'Assessment of Relationship between Young Researchers and Mentors and Implications for Knowledge Transfer.' Management 12 (3): 273-92.

Aspridis, G., and D. Kyriakou. 2012. 'Human Resource Evaluation in Hotel Units.' Management 7 (1): 17-34.

Basol, O., and I. Karatuna. 2017. 'Entrepreneurial Self-Efficacy of University Students: A Cross-Cultural Study.' Management 12 (1): 27-40.

Brinkschröder, N. 2014. 'Strategy Implementation: Key Factors, Challenges and Solutions.' Paper presented at the 4th IBA Bachelor Thesis Conference, Enschede, 6 November.

Chang, J. F. 2006. Business Process Management Systems: Strategy and Implementation. New York: Auerbach.

Cristian-Liviu, V. 2013. 'Organizational Culture and Strategy. How Does It Work? An Empirical Research.' Annals of the University of Oradea: Economic Science Series 22 (1): 1690-96.

Daghfous, A., O. Belkhodja, and L. C. Angell. 2013. 'Understanding and Managing Knowledge Loss.' Journal of Knowledge Management 17 (5). http://doi.org/10.1108/JKM-12-2012-0394

Deraman, F., N. Ismail, M. Arifin, A. Izzat, and M. I. A. Mostafa. 2017. 'Green Practices in Hotel Industry: Factors Influencing the Implementation.' Journal of Tourism, Hospitality \& Culinary Arts 9 (2): 112.

Dunlop, A., V. Firth, and R. Lurie. 2013. Dynamic Strategy Implementation: Delivering on Your Strategic Ambition. London: Deloitte University Press.

Grant, R. M. 2016. Contemporary Strategy Analysis: Text and Cases Edition. Chichester: Wiley.

Ha-Vikström, T. 2017. 'People, Process and Goal-Focused Leadership Behaviour: An Empirical Study in a Global Company.' Management 12 (1): 75-103.

- 2018. 'The People, Process and Goal Model versus the Sand Cone Model of Transformational Leadership: Critical Evaluation.' Management 13 (1): 71-90.

Herrera-Sánchez, I. M., J. M. León-Pérez, and J. M. León-Rubio. 2017. 'Steps to Ensure a Successful Implementation of Occupational Health and Safety Interventions at an Organizational Level.' Frontiers in Psychology 8. https://doi.org/10.3389/fpsyg.2017.02135

Jurevicius, O. 2013. 'McKinsey 7s Model.' Strategic Management Insight, 20 December. https://strategicmanagementinsight.com/tools/ mckinsey-7S-model-framework.html

Li, V., R. Mitchell, and B. Boyle. 2016. 'The Divergent Effects of Transformational Leadership on Individual and Team Innovation.' Group \& Organization Management 41 (1): 66-97.

Lubis, A., Z. B. Torong, and I. Muda. 2016. 'The Urgency of Implementing Balanced Scorecard System on Local Government in North 
Sumatra - Indonesia.' IOP Conference Series: Materials Science and Engineering 288. https://iopscience.iop.org/article/10.1088/1757 $-899 \mathrm{X} / 288 / 1 / 012081 / \mathrm{pdf}$

Misankova, M., and K. Kocisova. 2014. 'Strategic Implementation as a Part of Strategic Management.' Social and Behavioral Science 110:861-70.

Mkheimer, I. 2018. 'The Impact of Leadership Styles on Business Success: A Case Study on smes in Amman.' Arabian Journal of Business and Management Review 8 (2).

Netland, T. H. 2016. 'Critical Success Factors for Implementing Lean Production: The Effect of Contingencies.' International Journal of Production Research 54 (8): 2433-48.

Öztürk, R. B., and H. Demirkaya. 2017. 'The Relationship between Managerial Satisfaction and Job Turnover Intention: The Mediating Role of Job Satisfaction.' Management 12 (3): 235-48.

Palinkas, L. A., S. M. Horwitz, C. A. Green, J. P. Wisdom, N. Duan, and K. Hoagwood. 2015. 'Purposeful Sampling for Qualitative Data Collection and Analysis in Mixed Method Implementation Research.' Administration and Policy in Mental Health and Mental Health Services Research 42 (5): 533-44.

Powell, B. J., T. J. Waltz, M. J. Chinman, L. J. Damschroder, J. L. Smith, M. M. Matthieu, and J. E. Kirchner. 2015. 'A Refined Compilation of Implementation Strategies: Results from the Expert Recommendations for Implementing Change (ERIC) Project.' Implementation Science 10 (21): 1-14.

Rani, S., and K. Mishra. 2014. 'Green HRM: Practices and Strategic Implementation in the Organizations.' International Journal on Recent and Innovation Trends in Computing and Communication 2 (11): 36339.

Seale, A., N. Broutet, and M. Narasimhan. 2017. 'Assessing Process, Content, And Politics in Developing The Global Health Sector Strategy on Sexually Transmitted Infections 2016-2021: Implementation Opportunities for Policymakers.' PLos Medicine 14 (6). http://doi.org.10.1371/journal.pmed.1002330

Shomali, M., and M. Peeples. 2018. 'Implementation Strategy for a Digital Health Tool Influences User Engagement.' Diabetes 67 (Supplement 1). https://doi.org/10.2337/db18-1320-P

Sila, E., and K. Širok. 2018. 'The Importance of Employee Satisfaction: A Case Study of a Transportation and Logistics Service Company.' Management 13 (2): 111-36.

Spink, J., N. D. Fortin, D. C. Moyer, H. Miao, and Y. Wu. 2016. 'Food Fraud Prevention: Policy, Strategy, and Decision-Making-Implementation Steps for a Government Agency or Industry.' сніміA International Journal for Chemistry 70 (5): 320-28.

Springfield, R. 2017. 'Strategic Planning Process: Importance and Im- 
plications.' http://panmore.com/strategic-planning-process -important-business-management

Tarhini, A., H. Ammar, T. Tarhini, and R. Masa'deh. 2015. 'Analysis of The Critical Success Factors for Enterprise Resource Planning Implementation From Stakeholders' Perspective: A Systematic Review.' International Business Research 8 (4): 25-40.

Tourish, D. 2014. 'Leadership, More or Less? A Processual, Communication Perspective on the Role of Agency in Leadership Theory.' Leadership 10 (1): 79-98.

Van der Kolk, B., and T. Schokker. 2016. 'Strategy Implementation through Hierarchical Couplings in a Management Control Package: An Explorative Case Study.' Management Control 27 (2-3): 129-54.

Yeoh, W., and A. Popovič. 2016. 'Extending the Understanding of Critical Success Factors for Implementing Business Intelligence Systems.' Journal of the Association for Information Science and Technology 67 (1): 134-47.

This paper is published under the terms of the Attribution-

NonCommercial-NoDerivatives 4.o International (CC BY-NC-ND 4.0)

License (http://creativecommons.org/licenses/by-nc-nd/4.o/). 